УАK 347.965

ББК 67.75

DOI 10.22394/1682-2358-2017-5-138-145

A.S. Sarkisyan, post-graduate student, Povolzhsky Institute of Manazement named after P.A. Stolypin, Branch of the Russian Presidential Academy of National Economy and Public Administration

\section{THE CONTENT \\ OF LAWYER \\ ACTIVITIES \\ TO ESTABLISH \\ THE CIRCUMSTANCES OF A CRIMINAL CASE}

A lawyer's activities in establishing the circumstances of a criminal case are considered. Legal practices in criminal cases areanalyzed. The category of circumstances probability positions is studied. A comparative analysis of lawyer and investigator activities to establish the circumstances of a criminal case.

Keywords and word-combinations: cognition, cognitive activity, factual situation, lawyer.
A.С. Саркисян, аспирант кафедрь административного и уголовного праља Поволжского института управления имени П.А. Стольгпина - филиала Российской академии народного хозяйства и государственной служби при Президeнme РФ (email: armani9999@gmail.ru)

\section{СОАЕРЖАНИЕ

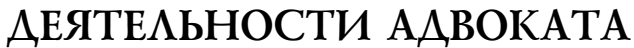 ПО УСТАНОВ АЕНИЮ

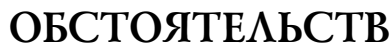 УГО $А$ ОВНОГО АЕ $\Lambda$ А}

\begin{abstract}
Аннотация. Рассматривается деятельность адвоката по установлению обстоятельств уголовного дела. Исследуется юридическая практика по уголовным делам, изучается категория позиций вероятности обстоятельств. Проводится сравнительный анализ деятельности адвоката и следователя по установлению обстоятельств дела.

Ключевые слова и словосочетания: познание, познавательная деятельность, фактические обстоятельства, адвокат.
\end{abstract}

A торому государство Аелегирует такую пубцичную функцию, как оказание гражданам квалифицированной юридической помощи. По словам Е.В. Васьковского, аАвокатура преАставмяет собой «защитницу прав гражАан во имя и в интересах общественного блага и явцяется таким же фактором правосудия, как суА и прокурорский надзор» [1, с. 2] . При этом законодательное закрепмение положения о том, что адвокатская деятельность - это априори квалифицированная юридическая помощь, обязывает 
адвокатуру соответствовать определенным ожиданиям общества, в том числе касающимся эффективности такой помощи.

ОАнако приходится констатировать, что во многих случаях проведенная адвокатами по уголовным делам защита не может быть охарактеризована как качественная. Многие авторы справедливо отмечают пассивность адвокатов, которые, не ожидая по уголовному деку положительного дмя доверителя результата, не предпринимают достаточных усилий по защите его прав и законных интересов. При проведении следственных действий адвокаты часто кишь формально принимают в них участие, придавая своим пассивным присутствием видимость состязательности. Распространены также случаи, когда адвокаты, например, не разъясняют подзащитным их права, не выясняют обстоятельства задержания, не уточняют, проводияся $и$ допрос в отсутствие адвоката и применялись $\Lambda и$ к подзащитному незаконные методы при проведении следственных действий или оперативно-розыскных мероприятий.

Адвокат является соотправителем правосудия, частью единого механизма, обеспечивающего надмежащее правоприменение при осуществлении угомовного преследования. Он выполняет важную функцию, представцяющую контраргументацию действиям следователя. Таким конфликтным взаимодействием элементов единого механизма обеспечивается достижение определенных законом целей уголовного преследования. Ненадлежащее исполнение адвокатом определенных законом обязанностей по установлению фактических обстоятельств дела, критической оџенке деятельности следствия, а также отсутствие реальных механизмов оценки эффективности и достаточности преАпринимаемых усилий нередко способны привести к формальному осушествлению функции защиты. Аекоративность такого элемента отправления правосудия по уголовным делам, в свою очередь, ставит под сомнение эффективность всего процесса уголовного преследования и его соответствие общепризнанным принџипам справедиивого правосудия.

КАючевым элементом осушествления аАвокатом защиты в уголовном судопроизводстве, безусловно, является его познавательная активность. Адвокат должен не просто пассивно ознакомиться с материалами уголовного дела, а использовать все средства и способы, предоставленные ему законодателем, Аля опровержения доказательств стороны обвинения и сбора всей возможной доказательственной информации в пользу своего доверителя. В том случае, когда адвокат не выясняет обстоятельства уголовного дела, юридическая помощь не может быть признана квалифицированной.

Бесспорно, аАвокат Аолжен проявцять требуемую для его профессии активность в отстаивании позиции своего подзашитного. Аля этого он обязан в первую очередь устанавливать обстоятельства уголовного дела, выдемяя благоприятные Аля своего доверителя, и использовать их в проџессе защиты. Конечно, основу Аля позиции по делу, как правицо, представцяют сами материалы уголовного дела. ОАнако и так называемая критика стороны обвинения также подразумевает активность адвоката: он отыскивает пробемы, 
выявцяет противоречия, находит процессуальные ошибки, допущенные на этапе предварительного следствия. Вместе с тем работа защитника не ограничивается мишь критикой обвинения, поскольку он обязан устанавцивать и иные, в том числе не обнаруженные следствием, обстоятельства, свидетельствующие в пользу своего подзащитного.Только такая познавательная активность может быть охарактеризована как квацифицированная юридическая помощь.

Установление аАвокатом обстоятельств уголовного дела явцяется одним из видов познания. Познание означает приобретение знания, постижение закономерностей объективного мира, способность познавать [2, с. 707]. Толковый словарь русского языка научным познанием называет проџесс ознакомления с новыми предметами, явлениями [3, с. 923] .

Сушествует точка зрения, что в Аеятельности, рассматриваемой под углом юридического познания, можно выделить три основных компонента: познание, интерпретацию (толкование) и принятие решения, то есть интерпретация отделяется от процесса познания. В рамках данной концепции интерпретации подлежат фактические обстоятельства, поведение и высказывания мюдей, имеющие юридическое значение.

В качестве равнозначного понятию познавательной деятельности в $\Lambda и-$ тературе, например в исследованиях М.В. Ходилиной, О.В. Головановой, используется термин «адвокатское познание». Полагаем, что Аанные термины могут применяться в контексте действий защитника как синонимы. О.В. Голованова называет адвокатское познание деятельностью, направленной на обстоятельства искомого события, задачей которой явцяется квацифиџированная юридическая помощь, итоговой целью - подкрепление позиции по Аелу, благоприятной Аля подзащитного [4, с. 7] .

Приведенная формулировка преАставляется не вполне удачной, так как задача подменяет собой итоговую цель защиты, которая, в свою очередь, определена простым обоснованием позиции, при этом не ясно, откуда может появиться сама позиция, если она вырабатывается до и вне познавательной Аеятельности защитника.

М.В. Ходилина определяет адвокатское познание как деятельность защитника, осуществляемую в целях получения требуемых сведений о событии и направленную на выявление обстоятельств, в том числе и их источников, которые защитнику необходимо будет доказать или опровергнуть, руководствуясь интересами своего подзащитного [5, с. 104-105]. Приведенное опреАеление представляет интерес, хотя и оно явмяется не бесспорным. Так, из него вытекает, что адвокат получает данные об обстоятельствах дела в целях определения положений, подлежкащих опровержению или подтверждению, однако такие обстоятельства уже определены уголовно-проџессуальным законодательством. Автор имец в виду правильный посыл - адвокат собирает свеАения в цемях формирования позиции по делу и ее Аальнейшего обоснования, но описал его не совсем точно.

Познавательная деятельность адвоката при осуществлении защиты по угоцовному Аелу преАставцяет собой мероприятия, направленные на получение 
требуемых сведений об исследуемом предмете - обстоятельствах уголовного дела. В связи с этим деятельность адвоката по установлению обстоятельств уголовного дела синонимична познавательной деятельности адвоката по угомовному делу и является отправной точкой в функщионировании по защите, основой осуществляемой защиты. Так адвокат, Авигаясь к намеченной цели, получает информаџию, необходимую ему дмя оказания квалифиџированной юридической помощи подзащитному.

Приведенный тезис можно подкрепить интересным примером из определения судебной коммегии по уголовным декам № 22-3312/15 от 28 мая 2015 г., в котором она отменила приговор в связи с нарушением права поАсудимого на защиту. Как следовало из протоколов судебного заседания, аАвокат на протяжении всего судопроизводства фактически никакого участия по защите подсудимого не принимац, то есть укмонияся от осуществления своих обязанностей по защите интересов подсудимого. Аалее, несмотря на высказанную подзащитным позиџию о признании протокола явки с повинной недопустимым доказательством, адвокат оставиц изучение этого вопроса на усмотрение суда, чем занял позиџию, противоположную позиџии своего подзащитного. Выступая в судебных прениях, адвокат мишь огласим протокол судебного заседания и высказал свою позицию по предъявленному обвинению в совершении преступления, преАусмотренного ч. 3 ст. 30, пунктом «а» ч. 2 ст. 228.1 УК РФ, не высказав своей позиџии по обвинению поАзащитного в совершении преступления, предусмотренного ст. 316 УК РФ, чем фактически отказался от защиты подсудимого. На основании изможенного судебная коммегия пришла к выводу, что подсудимый бым кишен юридической помощи в судебном заседании, а это могло повлиять на принятие судом правильного решения [6] .

Установление адвокатом обстоятельств уголовного дела, или, как уже было отмечено, познавательная деятельность адвоката, в гносеологическом плане может рассматриваться и в качестве проџесса, и в качестве результата - как правовая оџенка изучаемых отношений, юридический вывоА [7, с. 112]. Разбор же указанной деятельности адвоката в качестве процесса предполагает диалектику проџесса познания: от незнания - к знанию; от неполного и неточного знания - к более полному и точному.

Так, в соответствии с диалектикой раз есть субъективное, то должно быть и объективное, если есть вероятность, непременно должна быть и достоверность [8, с. 51]. Применительно к деятельности адвоката по установлению обстоятельств уголовного дела путь от незнания к знанию означает, что он, собирая и проверяя информацию, встречает препятствия, обнаруживает ее недостатки, осуществляет поиск новых сведений об обстоятельствах дела $[9$, c. 119].

В связи с этим адвокат в проџессе установления обстоятельств дела часто оперирует категорией вероятности. Вероятность Аця него в этом случае есть средство установления обстоятельств дела, способ выражения результатов на Аанном уровне его поиска. При этом такое вероятное 
суждение представмяет путь адвоката к завершенной истине [10, с. 50]. В связи с этим вспомним высказывание Р. Аекарта, что кучше не заниматься познанием вовсе, чем заниматься предметами настолько трудными, что, буАучи не в состоянии отличить в них истинное от Аожного, мы вынуждены допускать сомнительное в качестве Аостоверного, ибо в этих случаях надежда на приумножение знания не так велика, как риск его убавмения [11, с. 80]. Применительно к деятельности адвоката приведенное суждение можно понимать как ошибку адвоката, который воспринимает

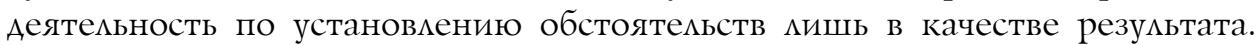
Вместо того, чтобы, отталкиваясь от получаемых сведений, Авигаться «от незнания к знанию», адвокат останавцивает познавательный процесс, Аопуская вероятные обстоятельства дела в качестве достоверных. Очевидно, что выстроенная на таких вероятных обстоятельствах позиџия аАвоката по Аелу как минимум может не дать положительного итога принятой аАвокатом на себя защиты, а как максимум приведет к прямому негативному результату Аля его доверителя.

Разумеется, познавательная деятельность адвоката выходит за рамки мысмительной, поскольку поиск юридически значимых обстоятельств произошеАшего в прошиом события подразумевает совершение адвокатом активных Аействий, направленных на их установление.

В подтверждение Аанного тезиса приведем пример из Аисциплинарной практики ААвокатской палаты Московской обцасти. Как указано в жалобе, аАвокат осуществлям защиту подсудимого в апемцяџионной инстанџии по соглашению. По мнению заявителя жкалобы, адвокат ненадлежащим образом исполнял свои обязанности, защита, осуществляемая аАвокатом, не была добросовестной и профессиональной ввиду полнейшей неподготовменности адвоката. Однако квацификаџионная комиссия установица, что представценными материалами аАвокатского досье опровергаются доводы жалобы, а также отметила, что в возражениях гособвинитемя на апемцяционную жалобу прямо указывается, что аАвокат «занимац активную позицию, заявляя ходатайства, задавая вопросы свидетелям в том объеме, который свидетельствовац о свободном оперировании имевшимся в материалах Аела массивом Аоказательств» (Заключение квалификационной комиссии ААвокатской палаты Московской обцасти (ЗКК АПМО) № 20-08/14) $[12$, с. 95].

Таким образом, содержанием деятельности адвоката по установлению обстоятельств уголовного дела явцяется поиск значимой информаџии об исследуемом событии. Тем не менее при изучении психологических особенностей осуществления познавательной деятельности авторы научных трудов обходят аАвокатов стороной, уделяя основное внимание психологической структуре деятельности следователей и судей [13, с. 411] .

В ракурсе юридической психологии деятельность следователя по установмению обстоятельств дела не имеет значительных отличий от аналогичной деятельности адвоката, хотя, безусловно, и задачи, и средства, и конечные 
цели сторон различны. Как и у следователя, начальным пунктом деятельности адвоката явмяется возникновение проблемной поисковой ситуации, означающей наличие совокупности обстоятельств совершенного преступцения с недостатком информаџии, получение которой требует инициативы адвоката по ее установлению. Именно поэтому базовым компонентом психологической структуры его работы становятся действия по установцению обстоятельств уголовного дела, то есть по сбору и исследованию фактов, относящихся к событию преступления [13, с. 418]. С точки зрения психологии, адвокат, как и следователь, когда выстраивает первые версии, делает абстрактные (отвлеченные) предположкения, затем вылвигает новые дополнительные варианты и, наконец, с учетом имеющейся уже накопменной информации о преступлении, на основе своих знаний, профессионального и житейского опыта имеет возможность оценивать правдоподобность различных выдвинутых версий по Аелу $[10$, с. 65$]$.

Кроме того, как и у следователя, у защитника проџесс установления всех обстоятельств дела - глубоко психологизированный процесс опосредованного отражения действительности. Поскольку каждое событие, включая и событие преступления, отображается как в материальном мире, так и в психике мюдей, предметом деятельности аАвоката, аналогично деятельности следователя, становятся взаимосвязи непосредственно воспринимаемых явлений и представления, отразившиеся в сознании мюдей, о преступлении [14, c. $122-123]$.

То, что главные объекты деятельности адвоката по установлению обстоятельств уголовного дела представляют собой события прошлого, является характерной особенностью деятельности адвоката. ОАнако указанным событиям прошиого, как правило, сопутствуют важные события настоящего, устанавливая которые, адвокат выявмяет их связи с прошлым и по ним устанавливает обстоятельства уголовного дела [15, с. 368] .

Процесс установления обстоятельств дела происходит путем совершения адвокатом практических действий, направленных на получение требуемых сведений, и мыслительных операций по их обработке. В.А. Аазарева отмечает, что это позволяет разграничить Ава относительно самостоятельных уровня такой деятельности. На первом уровне адвокат непосредственно получает информацию, которая поступает с помощью органов чувств, в связи с чем его можно охарактеризовать как чувственно-практический (эмпирический). Аалее происходит анализ и синтез собранной информации, а также формулирование нового тезиса и его дальнейшее обоснование, что позволяет назвать второй уровень рационально-логическим [16, с. 23] .

Получение сведений через органы чувств представцяет собой непосредственное отражение предметов и явлений объективного мира и проявмяется в трех возможных формах: ощущении, восприятии, представлении. Рациональный уровень предполагает, в свою очередь, проникновение мысли в суть явлений, установление связей межАу ними, когда адвокат может восстановить цемостную картину события $[17$, с. 13$]$. 
По аналогии с содержанием познавательной деятельности суда, исследованным в работе $\Lambda$.А. Воскобитовой, отметим, что содержание познавательной деятельности защитника в современном уголовном судопроизводстве включает смедующее: 1) познание информаџии, которую дает сторона обвинения, и проверку ее достоверности, полноты, непротиворечивости; 2) содержательный и формально-логический анализ этой информации с целью выявления пробелов, сомнений, противоречий; 3) устранение выявленных недостатков и разрешение собственных познавательных вопросов с целью обеспечения реамизации защитительной позиџии [18, с. 109] .

В процессе мышления чемовек оперирует материалом, достигнутым в ходе чувственной и интемлектуальной переработки мира, преобразовывает полученные результаты, углубцяется в суть вещей благодаря абстрагированию, движется в обратном направлении - в область конкретного.

А.А. Сиразутдинова отмечает, что деятельность защитника неразрывно связана с познавательным процессом (мышиением), развитием всех мыслительных операций (анализа, синтеза и Аругих). Существенную роль играет и умение предвидеть все этапы дела от предварительного расследования до рассмотрения дела в суде и развития событий после судебного разбирательства. Особенность мышления защитника проявляется в постоянном анализе и сравнении собственных действий и поступков с поведением Аругих миџ [19, c. 137].

Указанные суждения имлюстрируют работу адвоката. Сначама защитник собирает эмпирический материал, информацию о произошедшем событии и иных обстоятельствах дела. Указанная информация подмежит осмыслению, чтобы на ее основе адвокат смог вывести новое знание: построить модель события, выдвинуть первые версии защиты, наметить дальнейшие шаги. Следующий этап, как правицо, заключается в претворении нового выводного знания в ходе уголовного судопроизводства. В результате адвокат собирает определенную совокупность подлежащих исследованию обстоятельств дела, которые в Аальнейшем будут составцять основу его правовой позиции.

Эффективное использование средств и способов защиты невозможно без установления фактических обстоятельств уголовного дема, поскольку поисковая ситуаџия, возникающая переА адвокатом при принятии защиты по делу, становится одновременно и отправной точкой оказания им юридической помощи, и процессом, сопровождающим деятельность адвоката на протяжении всей защиты по уголовному делу. Содержанием деятельности адвокатазащитника по установлению обстоятельств уголовного дела является поиск благоприятной дмя подзащитного юридически значимой информаџии о преступцении, объектом выступает само событие преступления. Сначала адвокат получает информацию об исследуемом событии - обстоятельствах уголовного дела, затем идет процесс обработки полученной информации, на ее основе формируется новое знание, тезис, который и опредемяет дальнейшую деятельность по установлению обстоятельств дела. 


\section{Библиографический список}

1. Васьковский Е.В. Основные вопросы адвокатской этики. СПб., 1895.

2. Ожегов С.И. Словарь русского языка / под общ. ред. Л.И. Скворцова. 24-е изд., испр. M., 2012.

3. Толковый словарь русского языка / под ред. Д.В. Дмитриева. М., 2003.

4. Голованова О.В. Адвокатское познание по уголовному делу: дис. ... канд. юрид. наук. Н. Новгород, 2008.

5. Ходилина М.В. Правовая позиция адвоката-защитника (проблемы формирования и реализации): дис. ... канд. юрид. наук. М., 2013.

6. Бюллетень судебной практики Московского областного суда за второй квартал 2015 г., утв. президиумом Мособлсуда 9 сент. 2015 г. [Электронный ресурс]. Доступ из СПС «КонсультантПлюс».

7. Аверин А.В. Истина и судебная достоверность (Постановка проблемы). 2-е изд., доп. СПб., 2007.

8. Быков В.М., Печников Г.А. Об установлении истины в уголовном судопроизводстве // Журнал российского права. 2004. № 3.

9. Володина Л.М., Володина А.Н. Уголовное судопроизводство: право на справедливую и гласную судебную защиту. М., 2010.

10. Овсянников И.В. Категория вероятности в судебной экспертизе и доказывании по уголовным делам: дис. ... д-ра юрид. наук. М., 2001.

11. Декарт Р. Сочинения: в 2 т. / пер. с лат. и франц; сост., ред., вступ. ст. В.В. Соколова. M., 1989. T. I

12. Орлов А.А. Профессиональная этика адвоката: опыт правоприменения дисциплинарных органов Адвокатской палаты Московской области. М., 2016.

13. Сорокотягин И.Н., Сорокотягина Д.А. Юридическая психология: учебник для вузов. 3-е изд., перераб. и доп. М., 2014.

14. Еникеев М.И. Юридическая психология: учебник. М., 2013.

15. Романов В.В. Юридическая психология: учебник для бакалавров. 5-е изд., перераб. и доп. М., 2012.

16. Лазарева В.А. Доказывание в уголовном процессе: учебно-практическое пособие. 3-е изд., перераб. и доп. М., 2012.

17. Артамонова E.A., Фирсов O.B. Основы теории доказательств в уголовном процессе России: учебное пособие. М., 2014.

18. Воскобитова Л.А. Познавательная деятельность суда в уголовном судопроизводстве // LexRussica (Русский закон). 2005. № 1.

19. Сиразутдинова А.А. Процессуальные, тактические и психологические аспекты участия защитника в предварительном расследовании: дис. ... канд. юрид. наук. Екатеринбург, 2008. 